\title{
ANA MARIA LISBOA DE MELLO": "a crítica do imaginário responde às nossas inquietações sobre a linguagem, o sentido, a interpretação de nosso lugar na sociedade".
}

A Téssera tem a honra de oferecer em seu primeiro número uma entrevista com Ana Maria Lisboa de Mello, cujas perguntas partiram de membros do GT "Imaginário, representações literárias e deslocamentos culturais". Ana Lisboa é uma das primeiras pesquisadoras brasileiras a abordar a literatura pela crítica do imaginário. Nesta entrevista, a professora constrói um pensamento e revisa conceitos de tal forma que o leitor poderá compreender os fundamentos e o percurso dessa crítica, desde a definição do termo "imaginário", cunhada por Gilbert Durand e Jean-Jacques Wunenburger, até uma infinidade de autores e obras de teorias e críticas sobre o imaginário. As reflexões aqui expostas tornam essa entrevista indispensável aos estudiosos das imagens, dos símbolos e dos mitos.

Mairim Piva: Como foi seu primeiro contato com as teorias do imaginário? O que te levou a essa linha de pesquisa?

Quando ingressei no mestrado, já tinha a ideia de escrever sobre os grandes eixos temáticos da poesia de Cecília Meireles, minha poeta preferida, a partir dos 18 anos, após ler o livro Metal Rosicler da Biblioteca Municipal de Porto Alegre. Com a leitura sucessiva e frequente dos poemas completos da autora, percebi que eram recorrentes na lírica ceciliana os seguintes temas: a concepção do Absoluto, o incondicionado, princípio fundamental do qual tudo deriva; a visão do Relativo - a vida na realidade cósmica - assentada na efemeridade de tudo; o reconhecimento de um eterno retorno de tudo que compensa a tristeza das perdas; a concepção da vida como um exílio temporário onde se realizam aprendizagens. Essa visão da vida expressa-se por uma linguagem simbólica, sustentada por metáforas complexas, nas quais a analogia, para aludir ao inefável, constrói o sentido abstrato. No capítulo "Metáfora e símbolo",

\footnotetext{
${ }^{1}$ Fez estágios de pós-doutoramento no Centre de Recherches sur l' Imaginaire, na Université Stendhal, Grenoble III (1995-96), com bolsa do CNPq; na Sorbonne Nouvelle - Paris III (2004), com bolsa da CAPES; na University of Toronto (2013-2014), com bolsa CAPES. Após sua docência na UFRGS e na PUCRS, em 2017 vincula-se ao Programa de Pós-Graduação em Letras Neolatinas- PPGLEN, da UFRJ. De sua vasta produção, destacam-se Poesia e imaginário (2002); Oriente e Ocidente na poesia de Cecília Meireles (2006), em parceria com Francis Uteza. Coorganizações: Tessituras do imaginário poético: ensaios de poesia moderna (2013) Momentos da Ficção Brasileira (2016); Literatura e História: encontros contemporâneos (2016); Literatura e Filosofia: encontros contemporâneos (2015); O duplo: um estudo psicanalítico, de Otto Rank (2013); Escritas do Eu: introspecção, memória e ficção (2013).
} 
do livro Teoria da Interpretação: o discurso e o excesso de interpretação, de Paul Ricoeur explica a diferença entre esses dois recursos de linguagem.

Ao terminar o mestrado, senti necessidade de pesquisar sobre teoria do poema, sobretudo a rede imagética em poemas com teor metafísico e minhas leituras em francês levaram-me aos estudos do imaginário. Havendo pouca bibliografia sobre isso no Brasil, solicitei em 1988, durante o doutorado, um auxílio do CNPq para pesquisar na Université de Savoie, cidade de Chambéry, na França, porque lá Gilbert Durand havia organizado o primeiro Centre de Recherches sur l'imaginaire em 1966. Li sobre esse Centro em texto de Gilbert Durand, que compunha o livro de René ALLEAU, A ciência dos símbolos, publicado pelas edições 70. Em Chambéry encontrei muita bibliografia sobre o simbólico, o mito e o imaginário, que não havia no Brasil, porque não era um assunto que se pesquisava aqui. O Centre está localizado em um prédio exclusivo para ele, em dois andares, e com livros que Durand adquiriu com apoio da Universidade. No subsolo, encontrei uma bibliografia rara e qualificada sobre alquimia, com textos em grego e latim clássicos e em diferentes línguas modernas. Havia também Anais dos congressos, revistas com textos de grandes pesquisadores do campo das humanidades.

TES: Já havia uma cátedra nas universidades brasileiras voltada para literatura e imaginário? Não havia nada ainda no campo da literatura. Talvez a minha tese, defendida em maio de 1991, tenha sido a primeira da área de Letras ou uma das primeiras a abordar a literatura pela crítica do imaginário. Nas áreas de Antropologia, Sociologia e Educação havia trabalhos anteriores. No campo da Antropologia, por exemplo, Danielle Perin Rocha-Pitta (UFPE) foi precursora dos estudos sobre o imaginário no Brasil e fundadora do primeiro Centro de Pesquisas do Imaginário na Fundação Joaquim Nabuco, em Recife, em 1975, que passou para a Universidade, associado ao Pós-graduação em Antropologia, em 1992, como Núcleo Interdisciplinar de Pesquisas sobre o Imaginário. Atualmente, mais de 70 grupos de pesquisa registrados no $\mathrm{CNPq}$ estão ligados aos estudos do imaginário e há muitos núcleos e centros de pesquisas sobre o imaginário nas universidades brasileiras. Portanto, dos anos 1990 para cá, a área de investigação centrada no imaginário desenvolveu-se consideravelmente no Brasil. 
Mairim Piva: Quais foram as primeiras obras literárias que você analisou sob o viés do imaginário?

Em 1986, publiquei "Mar-origem e renovação da vida em Cecília Meireles", em que abordei a retomada da força mítica da imagem marítima em Mar Absoluto (1945), de Cecília Meireles. Coordenei, nesta época, a coleção " Era uma vez Perrault", pela editora Kuarup, de 1987 a 1993, em que, a cada volume de conto traduzido de Charles Perrault, havia uma leitura psicanalítica do conto, feita por um especialista (os primeiros volumes por Sérgio Messias) e uma leitura na perspectiva do imaginário que eu elaborei. As duas primeiras obras de poesia foram Solombra, de Cecília Meireles, e Poesia em pânico, de Murilo Mendes, corpus da tese, de 1991. Depois, sucederam-se outras publicações ao longo das décadas seguintes.

TES: Quando você chegou à universidade francesa para o seu doutoramento, tudo era novidade no campo do imaginário ou você já conhecia alguns textos básicos?

Como observei acima, durante o doutorado, em 1988, fui para o Centre de Recherches sur l'imaginaire, da Universidade de Savoie, mas antes de fazer essas pesquisas na França, li Les structures anthropologiques de l'imaginaire (Paris: Bordas, 1984), de Gilbert Durand, que só foi traduzido em Portugal em 1989 pela editora Presença; li também, em espanhol, La imaginación simbólica (Buenos Aires, ed. Amorrortu, 1971), de Gilbert Durand; A poética do mito (Forense, 1987), de E. M. Mielietinski; A Ciência dos símbolos (Lisboa, ed. 70), de René Alleau. Além desses, a obra de Gaston Bachelard, Paul Ricoeur, E. Cassirer, C.G. Jung, Mircea Eliade, Erich Neumann, entre outros.

Mairim Piva: Você se lembra do nome de seu primeiro orientando na linha de pesquisa do Imaginário? O que ele pesquisou? Em qual Universidade e quando?

Sim, foi uma aluna da Universidade Federal de Goiás, primeira Universidade Federal em que trabalhei. A dissertação intitula-se "A estrutura labiríntica de Memórias de Lázaro, de Adonias Filho", de 1993, de Áurea Sousa Oliveira de Abreu. Destaco também a dissertação de Eva Pereira da Cruz, intitulada " Imã, imagem, imaginação em Augusto dos Anjos" (1996), defendida na UnB, onde trabalhei mais de dois anos, e as teses de doutorado de Antonio Donizete da Cruz, intitulada "O universo imaginário e o fazer poético de Helena Kolody" (2001), e a de Áurea Sousa Oliveira Abreu, intitulada "A simbólica da passagem iniciática nas estórias de Guimarães Rosa" (2002), ambas na UFRGS. Esses são alguns trabalhos sob a 
perspectiva da crítica do imaginário, mas foram muitas orientações nessa linha crítica, incluindo TCCs, ICs, Mestrados e Doutorados.

Sueli Regino: Você diria que ocorre discriminação em algumas Universidades em relação aos estudos do Imaginário?

No âmbito das Letras, ocorreu muito no início de meu trabalho, porque não era um campo de pesquisa e uma abordagem teórica com os quais os docentes e pesquisadores trabalhavam nas universidades. Os estudos do imaginário, para alguns, significava a análise interpretativa de obras com conteúdo descolado da realidade social. Como há uma tradição, na área de Letras, sobretudo nas disciplinas de Literatura Brasileira, no sentido de que a literatura funcione como uma interpretação dos problemas sociais do País, toda obra literária que não facilite a abordagem sociológica da literatura, é desvalorizada.

Durand, na Introdução de As estruturas antropológicas do imaginário (1a edição de 1882), considera o imaginário como o conjunto de imagens e de relações entre imagens que constituem o capital pensado do homo sapien, de modo que esse conceito revela a amplitude do campo do imaginário.

Conforme assinala Jean-Jacques Wunenburger ${ }^{2}$, o termo imaginário (substantivo) concorre ou se aproxima de outros conceitos e áreas de pesquisa, tais como a "história da mentalidade", foco da escola história francesa dos Annales, voltada ao estudo de atitudes e comportamentos de uma dada sociedade em um tempo determinado; "mitologia", que reúne relatos de feitos de personagens divinas e humanas que traduzem crenças, valores, normas de uma determinada cultura; "ideologia", termo que implica uma interpretação global de um determinado da vida humana, como o político, o religioso, que se constrói com estereótipos, imagens-força (a luta de classes, por exemplo, na ideologia marxista) ${ }^{3}$; "ficção", ou seja, tudo que não corresponde à realidade, invenções, na qual a palavra imaginário pode funcionar como adjetivo (sinônimo de ficcional); "temática", no domínio da tematologia, termo utilizado em literatura comparada que se volta ao estudo de temas e motivos recorrentes em uma obra literária, portanto, ao imaginário de um texto escrito. A crítica temática está ligada, na França, ao nome de Jean-Pierre Richard,

\footnotetext{
${ }^{2}$ Cf. WUNENBURGER, Jean-Jacques. O imaginário. Trad. de Maria Stela Gonçalves. São Paulo: Loyola, 2007, 8-11

3 Nota: Assinala Wunenburger que a ideologia pode-se enxertar em um mito e valer-se do mito para dele se beneficiar, fortalecendo a interpretação de determinado campo ideológico. Id. Ib., p. 9.
} 
e recebeu a melhor definição na Introdução de sua obra $L^{\prime}$ Univers imaginaire de Mallarmé (1961). Nesse conjunto de abordagens, destacaria o estudo do mito como uma arquimemória da humanidade, que surge no imaginário de todas as épocas e é um aspecto relevante das teorias do imaginário. No âmbito da criação artística, o mito é como o deus Proteus, em constante metamorfose.

O historiador Lucien Boia, autor de Pour une histoire de l'imaginaire, observa que é preciso superar a dicotomia real/imaginário e renunciar à Razão como medida de todas as coisas. Segundo esse autor, o "imaginário mistura-se à realidade exterior e se confronta com ela; nela encontra pontos de apoio ou, ao contrário, um meio hostil; ele pode ser confirmado ou repudiado." ${ }^{4}$ Observa, ainda, que o "imaginário é produto do espírito", razão pela qual a sua concordância ou não com o que se acha fora dele é secundária, ainda que não desprovida de importância para o historiador.

Wunenburger, fundamentado no pensamento de Gaston Bachelard e na definição de Gilbert Durand, na obra acima citada, define o imaginário, sublinhando a sua função simbólica: "o imaginário [é] um conjunto de produções, mentais ou materializadas em obras, com base em imagens visuais (quadro, desenho, fotografia) e linguísticas (metáfora, símbolo, relato), formando conjuntos coerentes e dinâmicos, referentes a uma função simbólica no sentido de ajustes de sentidos próprios e figurados 5 .

Gaston Bachelard e, em seguida, Gilbert Durand põem em evidência a dimensão simbólica da imagem e o dinamismo organizador da imaginação. O imaginário ultrapassa o campo exclusivo das representações sensíveis. Ele compreende ao mesmo tempo as imagens percebidas (e inevitavelmente adaptadas, pois não existe uma imagem idêntica ao objeto), imagens elaboradas e ideias abstratas estruturando essas imagens.

Maria Goretti Ribeiro: Há na Europa do século XXI uma resistência do imaginário ou uma resistência ao imaginário?

Na Europa há muitos Centros de Pesquisa sobre o imaginário, em vários países, que fazem intercâmbios, eventos, publicações. Pode-se dizer que hoje é de mais fácil a aceitação dessa corrente teórico-crítica do que nos anos de 1960, quando foi criado o primeiro Centro de Pesquisas sobre o imaginário por Durand, porque naquela época as correntes sociológica e

\footnotetext{
${ }^{4}$ BOIA, Lucien. Pour une histoire de l'imaginaire. Paris: Belles Lettres, 1998, p. 16.

${ }^{5}$ WUNENBURGER, op. cit., p. 11
} 
marxista estavam em alta, com críticos como Lucien Goldman (1913-1970) e Georg Lukács (1885-1971), e a Escola de Frankfurt ( Adorno, Horkheimer, Benjamin), entre outros.

Maria Goretti Ribeiro: $O$ que se conserva em França do Centre de Recherches sur l'Imaginaire?

Os centros ou laboratórios de pesquisa sobre o imaginário são muitos na França. $\mathrm{O}$ da chamada Escola de Grenoble - Centre de recherche sur l'imaginaire/ CRI, fundado por Gilbert Durand - fundiu-se como o Laboratoire de Sociologie Émotion, Médiation, Culture, Conaissance de Grenoble e agora constituem o Centre de recherche Imaginaire et Socio-Anthropologie, de vocação pluridisciplinar e fazem parte da Unidade de pesquisa LITT\&ARTS. Destaco o Centre Gaston Bachelard de recherches sur l'imaginaire et la racionalité, da Universidade de Bourgogne, associado a Jean-Jacques Wunenburger.

Fundada em 2012 na Romênia, a Rede Internacional dos Centros de Pesquisa sobre o Imaginário (CRI2i) reúne uns quarenta centros de pesquisa franceses e vários de outros países (Europa, Coreia, Brasil, América do Norte). Cf. https://aacri.hypotheses.org/174

Maria Goretti Ribeiro: A quem poderíamos chamar grande expoente dos estudos do imaginário nestes tempos na Europa?

São muitos os grandes autores do imaginário na contemporaneidade, mas posso citar alguns: o filósofo Jean-Jacques Wunenburger (Universidade Jean Moulin Lyon 3), especialista em Gaston Bachelard e teorias do imaginário; Michel Maffesoli, da Universidade Paris-Descartes; Andrés Ortiz-Osés, professor de Hermenêutica na Universidade de Deusto, Bilbao, Espanha, com inúmeras publicações sobre o imaginário; Joël Thomas, da Universidade de Perpignan, França; Lucien Boia, historiador da Romênia, Pierre Brunel, da França. Mas são muitos os que estão ligados aos centros de pesquisa sobre o imaginário no mundo e citar alguns implica esquecer muitos.

Maria Goretti Ribeiro: Por que os grupos de pesquisa brasileiros sobre Imaginário pouco falam de grandes estudiosos da estirpe de Roger Callois, de Edgar Morin, René Alleau?

Não sei dizer, mas creio que o campo de estudos abriu-se tanto e agora contempla o que Durand previu ao dizer que o imaginário é a encruzilhada onde vêm se encontrar todas as Ciências Humanas. Nesse sentido, as abordagens teóricas são muitas e há que se fazer escolhas, de 
acordo com o corpus selecionado para abordagem. Por exemplo, se a pesquisa for sobre o imaginário metafísico, é preciso selecionar obras de autores que se dedicaram a essa questão como Henri Corbin (com conceito de mundus imaginalis), Françoise Bonardel (Philosophie et alchimie), Antoine Faivre, Ivette K. Centeno.

TES: Das hermenêuticas que fundamentam os estudos do imaginário, qual delas mais desperta seu interesse, a psicologia analítica, a filosofia, a história...?

Como o imaginário é esse campo multidisciplinar, que reúne todas as ciências humanas, penso que uma abordagem ilumina a outra, eu reuni obras do campo da Filosofia (destacaria aqui a Hermenêutica de Paul Ricoeur e de Hans Gadamer) Sociologia, Antropologia, Psicanálise, sobretudo Jung e pós-junguianos. Destaco também a coleção Hermeneusis da Editora Anthropos de Barcelona, que traz a cada volume uma perspectiva de várias ciências humanas sobre o imaginário. As obras sugerem o apoio teórico-crítico a ser buscado.

Geam K: No período entre 1995 e 1996 você realizou seu pós-doutorado na Université Stendhal - Grenoble III. Que pesquisa você desenvolveu lá? Provavelmente teve momentos enriquecedores com o eterno mestre Gilbert Durand... Estou certo?

Lá, resolvi assistir como ouvinte aos cursos do mestrado e doutorado multidisciplinar. Assisti a cursos de Frédéric Monneyron sobre o mito de Don Juan, de Danièle Chauvin sobre o Apocalipse em Blake, de Philipe Walter sobre Mito e História; mas também me encantou localizar, na Biblioteca da Universidade, os Anais do Congresso Eranos. Foi muito surpreendente. O Grupo Eranos, fundado em 1933, tendo Jung como um dos seus fundadores, organizava Congressos anuais na cidade de Ascona, na Suiça, em torno de um tema combinado previamente. Alguns dos nomes que integravam esse Grupo são: Rudolf Otto, Gilbert Durand, C. G. Jung, Marie-Louise Von Franz, Heinrich Zimmer, Karl Kérenyi, Mircea Eliade, Henry Corbin, Erich Neumann, James Hillman, Andrès Ortiz-Osès.

Geam K: Como uma das pioneiras da propagação da teoria do Imaginário de Gilbert Durand no Brasil, como você avalia a reverberação dessa teoria nos estudos literários no nosso país? E no contexto da instituição que você faz parte?

Como disse antes, agora há muitos grupos do Diretório de Pesquisa do CNPq (mais de 70), pesquisando sobre o imaginário, em várias áreas das Ciências Humanas, e deve crescer porque, 
no Brasil, já não somos, predominantemente, seguidores de conhecimentos produzidos em outros países da Europa e da América do Norte. Esses núcleos de pesquisa sobre o imaginário estão avançando na criação de conhecimentos sobre o imaginário, associados à nossa cultura, que é muito rica. Na UFRJ, onde estou há quase dois anos, ainda não interagi com os pesquisadores sobre o imaginário.

Geam K: No início deste século, você nos presenteia com Poesia e Imaginário. Trata-se do volume 11, pertencente à coleção Memória das Letras, publicada em 2002 pela EDIPUCRS. Nela, você perfaz uma brilhante hermenêutica da poesia de Cecília Meireles e Murilo Mendes a partir dos estudos do imaginário. Como nasceu essa obra e o que ela representa na sua trajetória acadêmica?

Nasceu da necessidade de entender a linguagem simbólica. A poesia trabalha como uma dimensão da linguagem em que o não dito - apenas sugerido, como diria Mallarmé - é tão importante como o dito. Esse não dito é o simbólico ou aquilo que Paul Ricoeur chama de "excesso de significação" que não se esgota no nível da língua, mas fica além, reverberando. Como não havia muita bibliografia no Brasil, o estágio de 3 meses na Université de Savoie, no Centro de Pesquisa inaugurado por Durand em 1966, foi fundamental para desenvolver a tese. Reuni muita bibliografia e assisti a um curso de Jean Burgos, autor de Pour une poétique de l'imaginaire.

Geam K: Em Poesia e Imaginário, a obra Solombra, de Cecília Meireles, surge como um universo muito representativo da poesia da escritora brasileira, com poemas que perpassam temas universais e aparentam alcançar uma dimensão intemporal. Como você mesma descreve, essa obra remete à própria ideia de projeção de imagens e de trevas, inclusive associada à alma. Nesse sentido, a partir de sua análise hermenêutica dos símbolos do conjunto da obra, você afirma que essa poética reside na tensão entre os regimes diurno e noturno. Poderia explicar melhor essa tensão? E que imaginário coletivo é possível inferir a partir dessa obra? No regime diurno a noite é tenebrosa, é nela que surgem seres sobrenaturais (próprios da literatura fantástica), no noturno é benéfica, pode ser o momento de ultrapassar as fronteiras que nos separam de mundos transcendentes, como ocorre em Solombra. Na obra, o eu-lírico adentra paulatinamente na noite e vislumbra outras realidades, ou o que Corbin chamou de mundus imaginalis. Essa tensão existe na nossa vida, nos nossos medos e, ao contrário, na nossa 
religiosidade (no sentido etimológico de re-ligar ao transcendente), às vezes o caminho para o apaziguamento.

TES: No rigoroso estudo da poesia de Cecília Meireles e Murilo Mendes, em Poesia e imaginário, você mostra a riqueza da mitocrítica na revelação do poema: os símbolos revigorados, o nascimento de outros, a linguagem simbólica anterior à racional... No entanto, os estudos da mitocrítica quase sempre se voltam para a prosa. A que se atribui esse fenômeno? A ficção é realmente privilegiada nos estudos no imaginário, mas a poesia é menos abordada por qualquer corrente crítica, já que é um gênero menos estudado, inclusive nos cursos de Letras, razão pela qual há relativamente poucos especialistas, sobretudo no que se refere à teoria do poema. Um dos críticos que se dedicou à poesia, na perspectiva do imaginário, foi Jean Burgos, autor de Pour une poétique de l'imaginaire, o qual foi orientado por Gilbert Durand na Université de Savoie,

TES: Ainda em Poesia e imaginário, você discorre sobre os entrelaçamentos do mito, do ritmo e da poesia, cuja base comum é a repetição. Poderia falar mais sobre isso?

No poema, há sempre uma imagem-diretora que está no centro da rede imagética do poema. As demais imagens são como uma "repetição" ou desdobrando da imagem principal, e isso é uma forma de repetição que constrói uma rede e nos permite chegar a uma interpretação. Por sua vez, o ritmo também é feito de repetições que reforçam a rede imagética. Claro que o poeta cria de uma só vez, sem pensar nisso que nós, analistas do poema, identificamos. Um poema melancólico tende a ter um ritmo lento, com pausas no meio dos versos, e outros recursos sonoros que funcionarão como uma espécie de "redundância" ao sentido das palavras. A repetição de mesmos sons, cadência do verso, é uma das características do ritmo. O poema "Retrato" de Cecília Meireles revela que a lentidão dos versos, provocada pelas repetições de conjunções e advérbios, corresponde ao tom melancólico do poema. Nos versos de "Retrato", a seguir, a repetição da palavra "assim" refreia a precipitação rítmica do poema e corresponde à lentidão sugerida pelas imagens: "Eu não tinha esse rosto de hoje, /Assim calmo, assim magro, assim triste." 
TES: Como você explicaria a ausência de Octavio Paz, que você retoma em Poesia e imaginário, e mesmo de Northrop Frye, do pensamento monumental de Gilbert Durand?

Talvez essa falta se explique por algumas razões que ouso supor. A ausência de Octavio Paz pode ser explicada pelo fato de que Gilbert Durand não se dedicou ao gênero lírico; predominam nas suas análises do imaginário na literatura as obras literárias ficcionais. Quanto à obra do crítico canadense Northrop Frye, penso que um dos principais conceitos de Durand, inspirado em C.G.Jung, é o de arquétipo e esse conceito especificamente no contexto literário, enquanto Durand e outros pesquisadores a ele associados empregam o termo mais relacionado ao pensamento de Jung. Percebi essa diferença no uso deste conceito por um e por outro. Mas são apenas hipóteses.

TES: Após esses longos anos de estudos do imaginário, qual é a sua perspectiva em relação ao que já foi mapeado, o que você pressente como campos futuros do estudo do imaginário? O crescimento desses estudos. Muitas publicações surgirão nos centros do Imaginário. Penso que a crítica do imaginário agrega outras correntes críticas passadas e as ciências humanas para a interpretação do homem, da vida. Tende a prosperar porque responde às nossas inquietações sobre a linguagem, o sentido, a interpretação de nosso lugar na sociedade. Exige muito estudo, mas dá muitas respostas. 